\title{
Critical Roles of Thioredoxin in Nerve Growth Factor- Mediated Signal Transduction and Neurite Outgrowth in PC12 Cells
}

\author{
Jie Bai, ${ }^{1}$ Hajime Nakamura, ${ }^{1}$ Yong-Won Kwon, ${ }^{1}$ Itaro Hattori, ${ }^{1}$ Yoshimi Yamaguchi, ${ }^{2}$ Yong-Chul Kim, ${ }^{1}$ \\ Norihiko Kondo, ${ }^{1}$ Shin-ichi Oka, ${ }^{2}$ Shugo Ueda, ${ }^{1}$ Hiroshi Masutani, ${ }^{1,2}$ and Junji Yodoi ${ }^{1,2}$ \\ ${ }^{1}$ Department of Biological Responses, Institute for Virus Research, Kyoto University, Kyoto 606-8507, Japan, and ${ }^{2}$ Biomedical Special Research Unit, \\ Human Stress Signal Research Center, National Institute of Advanced Industrial Science and Technology, Osaka 563-8577, Japan
}

Thioredoxin (TRX) has a role in a variety of biological processes, including cytoprotection and the activation of transcription factors. Nerve growth factor (NGF) is a major survival factor of sympathetic neurons and promotes neurite outgrowth in rat pheochromocytoma PC12 cells. In this study, we showed that NGF induces TRX expression at protein and mRNA levels. NGF activated the TRX gene through a regulatory region positioned from -263 to $-217 \mathrm{bp}$, containing the cAMP-responsive element (CRE). Insertion of a mutation in the CRE in this region abolished the response to NGF. NGF induced binding of CRE-binding protein to the CRE of the TRX promoter in an electrophoretic mobility shift assay. NGF also induced nuclear translocation of TRX. 2'-Amino-3'-methoxyflavone, an inhibitor of mitogen-activated protein kinase kinase, which is a known inhibitor of NGF-dependent differentiation in PC12 cells, suppressed the NGF-dependent expression and nuclear translocation of TRX. Overexpression of mutant TRX (32S/35S) or TRX antisense vector blocked the neurite outgrowth of PC12 cells by NGF. Overexpression of mutant TRX (C32S/C35S) suppressed the NGF-dependent activation of the CRE-mediated c-fos reporter gene. These results suggest that TRX plays a critical regulatory role in NGF-mediated signal transduction and outgrowth in PC12 cells.

Key words: thioredoxin; nerve growth factor; PC12 cells; neurite outgrowth; redox; cAMP-responsive element

\section{Introduction}

Neural survival and differentiation are influenced by the cellular redox condition (Kane et al., 1993). Thioredoxin (TRX) is a small $12 \mathrm{kDa}$ multifunctional protein having a redox-active disulfide/ dithiol within its active site sequence, -Cys-Gly-Pro-Cys-, and operates together with NADPH and thioredoxin reductase as a protein disulfide-reducing system (Holmgren, 1985). Several reports have shown that TRX-dependent redox regulation is closely involved in the signal transduction mediated by activator protein-1 (AP-1), nuclear factor- $\kappa \mathrm{B}, \mathrm{p} 53$, apoptosis-signaling kinase 1 (ASK1), and p38 mitogen-activated protein kinase (MAPK; Hirota et al., 1997; Saitoh et al., 1998; Hashimoto et al., 1999; Ueno et al., 1999). TRX is widely distributed and induced by various stresses (Nakamura et al., 1997; Masutani et al., 1999). TRX expression is also elevated by hemin, an inducer of differentiation in K562 erythroleukemia cells (Kim et al., 2001), or cAMP analogues in retinal pigment epithelial cells (Yamamoto et al., 1997). In the regulatory region of the TRX gene, there are several promoter-specific transcription factor 1 binding mo-

Received July 12, 2002; revised 0ct. 9, 2002; accepted 0ct. 17, 2002.

This study was supported by a grant-in-aid for scientific research from the Ministry of Education, Culture, Sports, Science, and Technology of Japan and by a grant-in-aid for research for the future from the Japan Society for the Promotion of Science. We thank Y. Kanekiyo for secretarial help and A. Nishiyama, Y. Nishinaka, M. Tanito, T. Miura, and Y. Ishii for discussion.

Correspondence should be addressed to Dr. Hiroshi Masutani, Department of Biological Responses, Institute for Virus Research, Kyoto University, Kawahara-cho, Shogoin, Sakyo, Kyoto 606-8507, Japan. E-mail: hmasutan@virus.kyoto-u.ac.jp.

Copyright $\odot 2003$ Society for Neuroscience $\quad 0270-6474 / 03 / 230503-07 \$ 15.00 / 0$ tifs, an antioxidant-responsive element, and a putative cAMPresponsive element (CRE). In neuronal tissues, TRX is induced in astroglia after ischemia (Tomimoto et al., 1993) and in motor neurons after nerve injury (Mansur et al., 1998). TRX is known to have a cytoprotective effect against oxidative stress (Nakamura et al., 1994) and neuroprotective activity (Hori et al., 1994). Furthermore, overexpression of TRX in transgenic mice attenuates focal ischemic brain damage (Takagi et al., 1999). TRX was also reported as a neurotrophic factor for central cholinergic neurons and has neurotrophic activity (Endoh et al., 1993), although the molecular basis of this effect has not been elucidated.

Nerve growth factor (NGF) and the other members of the neurotrophin family, such as brain-derived neurotrophic factor, have profound effects on neurons, including the promotion of survival and differentiation (Lo, 1992). NGF has been reported as a potential therapeutic agent in neurodegenerative disorders linked to aging, such as Alzheimer's disease (Connor and Dragunow, 1998). The current understanding of these mechanisms depends mostly on studies of NGF action on the pheochromocytoma cell line PC12 (Greene and Tischler, 1976). On exposure to NGF, PC12 cells differentiate into sympathetic neuron-like cells. The signal is initiated by the binding of NGF to its high-affinity receptor TrkA on the plasma membrane (Kaplan et al., 1991) and transduced by activation of ras and the MAPK cascade (Thomas et al., 1992). NGF treatment in PC12 cells leads to the activation of immediate-early genes (IEGs), such as c-fos, which are believed to be critical to NGF action (Milbrandt, 1986). NGF activates the c-fos gene through several elements, including the serum re- 
sponse element (SRE; Treisman, 1986) and CRE (Ginty et al., 1994; Ahn et al., 1998).

The aim of the present study is to investigate the possible roles of TRX as a neurotrophic cofactor in NGF-dependent outgrowth of PC12 cells and the NGF-mediated signal transduction pathway. We report here that TRX plays an important role in the NGF-mediated signal transduction and neurite outgrowth in PC12 cells.

\section{Materials and Methods}

Cell lines and culture. NGF, polyethylenimine (PEI), and 2'-amino- $3^{\prime}$ methoxyflavone (PD98059) were purchased from Sigma (St. Louis, MO). Hoechst 33324 was purchased from Molecular Probes (Eugene, OR). Cells of the rat pheochromocytoma tumor cell line PC12 were maintained in RPMI 1640 medium (Invitrogen, Grand Island, NY) with $10 \%$ heat-inactivated horse serum and $5 \%$ heat-inactivated fetal calf serum (FCS) supplemented with antibiotics $(100 \mathrm{IU} / \mathrm{ml}$ penicillin and 100 $\mu \mathrm{g} / \mathrm{ml}$ streptomycin) at $37^{\circ} \mathrm{C}$ in a humid atmosphere containing $5 \%$ $\mathrm{CO}_{2}$.

Plasmids. The pTrx-chloramphenicol acetyltransferase (CAT) plasmids were constructed as described previously (Taniguchi et al., 1996). The HindIII-Bam HI inserts from the pTrxCAT vectors were subcloned into pBluescript II KS (+) (pTRXblue vectors). The pTRX (-1148)luciferase (Luc), pTRX (-1062)-Luc, pTRX (-352)-Luc, and pTRX (-263)-Luc vectors were constructed by ligating the KpnI-BamHI fragments of the pTRXblue vectors into the KpnI-BglII sites of the pGL3 basic vector (Promega, Madison, WI). The ApaI-PvuII insert of the pTRX (-263)-Luc vector was excised, filled in, and self-ligated to produce the pTRX $(-217)$-Luc vector. The pGL3-c-fos $(-40,+42)$ and pGL3-c-fos $(-99,+42)$ luc vectors were constructed by subcloning an MluI-HindIII fragment of the Fos-40 luc (Masutani et al., 1997) and the pFDE-luc vectors into the MluI-HindIII site of the pGL3 basic vector (Promega). SRE3-luc was constructed as described previously (Masutani et al., 1997). pFDE-luc was constructed by subcloning a BamHI-HindIII fragment of FDE-CAT (Trouche et al., 1993) into the BglII-HindIII site of the pGL2 basic vector (Promega). PTrxCREwt-Luc and pTrxCREmtLuc vectors were constructed by inserting CRE wild-type (wt) or CRE mutant (mt) oligonucleotides into the XhoI-PuvII site of the pTRX (-1148)-Luc, respectively. The $\operatorname{pCDSR} \alpha$-TRX, $\operatorname{pCDSR} \alpha$-TRX (C32S/ C35S), and pcDNA3TRX (32S/35S) vectors were constructed as described previously (Hirota et al., 1997, Nishiyama et al., 1999). The $B a m \mathrm{HI}$ inserts from pCDSR $\alpha$-TRX and $\operatorname{pCDSR} \alpha$-TRXm (Tagaya et al., 1989; Hirota et al., 1997) were subcloned into the BamHI site of pBluescript II KS [pBS-wtTRX, pBS-antisense, and pBS-double mutant $(\mathrm{dm})$ TRX]. pBI-enhanced green fluorescent protein (EGFP)wtTRX, pBI-EGFP-antisenseTRX, and pBI-EGFP-dmTRX (32S/35S) were constructed by ligating the EcoRV-XbaI fragments of the pBSwtTRX, pBS-antisense, and pBS-dmTRX vectors into the PvuII-NheI sites of the pBI-EGFP vector (Clontech, Palo Alto, CA), respectively. All the constructs were controlled by direct nucleotide sequencing using a Thermo Sequenase II dye terminator cycle sequencing kit (Amersham Biosciences, Arlington Heights, IL). The pRL-TK vector was purchased from Promega. pcDNA3 was purchased from Invitrogen. The oligonucleotides used for construction of vectors and the electrophoretic mobility shift assay (EMSA) were as follows: CREwt, forward, 5'-CGCCTCCCACCGTCACGGGCAGTGC-3'; and reverse, 5' -TCGAGCACTGCGCGTGACGGTGGGAGGCGGTAC-3'; and CREmt, forward, 5'-CGCCTCCCACTATCACGGGCAGTGC-3'; and reverse, 5' -TCGAGCACTGCGCGTGATAGTGGGAGGCGGTAC-3'.

Western blot analysis. Cells were collected and washed twice with icecold PBS, and then lysed with a solubilizing solution (10 mM Tris-HCI, pH 7.4, 150 mm NaCl, 1\% NP-40, 1 mm EDTA, 0.1 mM PMSF, $8 \mu \mathrm{g} / \mathrm{ml}$ aprotinin, and $2 \mu \mathrm{g} / \mathrm{ml}$ leupeptin) on ice for $30 \mathrm{~min}$. The extracts were cleared by centrifugation. Cell lysates were kept at $95^{\circ} \mathrm{C}$ for $5 \mathrm{~min}$ and then separated by $15 \%$ SDS-PAGE. The separated proteins were transferred to a polyvinylidene difluoride membrane (Millipore, Bedford, MA). The membrane was treated with $10 \%(\mathrm{w} / \mathrm{v})$ skim milk in PBS containing $0.05 \%$ Tween 20 overnight, and incubated with anti-mouse
TRX rabbit polyclonal antibody (dilution, 1:1000; Redox Bioscience, Inc.; Takagi et al., 1998c) for $1 \mathrm{hr}$, followed by peroxidase-conjugated anti-rabbit IgG (dilution, 1:5000; Amersham Biosciences) for $1 \mathrm{hr}$. The epitope was visualized with an ECL Western blot detection kit (Amersham Biosciences). We reported previously that this anti-mouse antibody cross-reacts with rat TRX (Takagi et al., 1998a,b).

Northern blot analysis. Total RNA was extracted using TRIzol reagent according to the manufacturer's instructions (Maruyama et al., 1997). Twenty micrograms of total RNA were electrophoresed and transferred to maximum-strength Nytran nylon (Schleicher \& Schuell, Keene, NH) with a Turbo-Blotter system (Schleicher \& Schuell). The filter was hybridized with a mouse TRX probe, which cross-reacts with rat TRX mRNA as reported previously (Takagi et al., 1998a,b).

Electrophoretic mobility shift assay. EMSA was performed as described previously (Kim et al., 2001). Nuclear extracts were prepared from exponentially growing PC12 cells incubated with NGF $(50 \mathrm{ng} / \mathrm{ml})$ at various time points. Aliquots of $10 \mu \mathrm{g}$ of unclear extracts were incubated with ${ }^{32} \mathrm{P}$-end-labeled double-stranded oligonucleotides in a binding reaction buffer containing 20 mM HEPES, pH 7.9, 0.02 mM EDTA, 14\% glycerol, $1 \mu \mathrm{g}$ of poly (dI-dC), $100 \mathrm{~mm} \mathrm{KCl,} 1.5 \mathrm{~mm} \mathrm{MgCl}$, and $0.02 \mathrm{~mm}$ DTT for $20 \mathrm{~min}$ at $25^{\circ} \mathrm{C}$. For specificity analyses, a 100 -fold molar excess of unlabeled oligonucleotide competitors was preincubated for $15 \mathrm{~min}$. When indicated, reaction mixtures were incubated with control antibody or anti-CRE-binding protein (CREB) antibodies (dilution, 1:10; Cell Signaling), which are specific to CREB and do not react with other members of the activating transcription factor family, for $20 \mathrm{~min}$ on ice before labeled oligonucleotides were added.

Transfection and luciferase assay. PC12 cells were seeded at $60 \%$ confluence in $35 \mathrm{~mm}$ dishes before transfection. Cells in the serum-free medium were transfected with PEI reagent as described previously (Boussif et al., 1995; Masutani et al., 1997). After 24 hr, transfected cells were treated with $50 \mathrm{ng} / \mathrm{ml} \mathrm{NGF}$ (Sigma). For controlling the efficiency of transfection, Renilla luciferase gene expression was monitored using pRL-TK. Luciferase gene expression, normalized by Renilla luciferase activity, was analyzed $24 \mathrm{hr}$ later using an assay kit (Promega) with a luminometer. The luciferase assays were performed in duplicate. The relative fold activation of luciferase activity was calculated. PC12 cells were cotransfected with a bidirectional expression vector, pBI-EGFP, pBI-EGFP-wtTRX, pBI-EGFP-antisenseTRX, or pBI-EGFP-dmTRX in which the active site of TRX is inactivated (Ueno et al., 1999), together with the pTet-Off vector (Clontech). After transfection, NGF was added to the medium. Cells expressing EGFP were examined with a fluorescent microscope (Bio-Rad, Hercules, CA) 24 or $48 \mathrm{hr}$ later.

Immunofluorescence cell staining. PC12 cells were seeded before staining at $60 \%$ confluence in culture slides coated with poly-L-lysine. The cells were then fixed with $3.7 \%$ paraformaldehyde in PBS containing $10 \%$ FCS for $20 \mathrm{~min}$ at room temperature, which was followed by permeabilization for 10 min using $0.2 \%(\mathrm{w} / \mathrm{v})$ Triton X-100 in PBS and blocking with PBS containing 5\% bovine serum albumin and $10 \%$ FCS for 20 min. Slides were incubated with $2 \mu \mathrm{g} / \mathrm{ml}$ mouse TRX antibody for $60 \mathrm{~min}$ and then washed with PBS. The slides were then incubated with $1 \mu \mathrm{g} / \mathrm{ml}$ fluorescein isothiocyanate-labeled secondary antibody (Molecular Probes) for $60 \mathrm{~min}$ and were again washed with PBS. Hoechst 33324 (10 $\mu \mathrm{g} / \mathrm{ml}$ ) was then added. Stained cells were examined using either the laser confocal or fluorescent microscope.

\section{Results}

\section{NGF induced TRX expression in PC12 cells}

We examined the effect of NGF on TRX expression in PC12 cells. The protein expression of TRX increased in PC12 cells 1.5 -fold at $24 \mathrm{hr}$ and 1.7-fold at $48 \mathrm{hr}$ after NGF treatment (Fig. 1A). TRX mRNA also increased $2 \mathrm{hr}$ after NGF treatment (Fig. $1 B$ ). To analyze the mechanism of induction of TRX by NGF treatment, we examined TRX promoter activity using PC12 cells transfected with TRX-Luc. Treatment with NGF significantly enhanced the activity of the TRX promoter (Fig. $1 C$ ). 


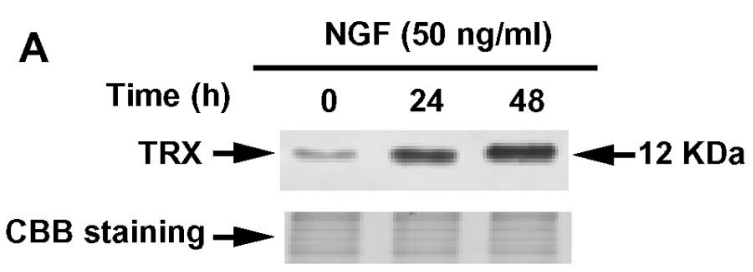

B
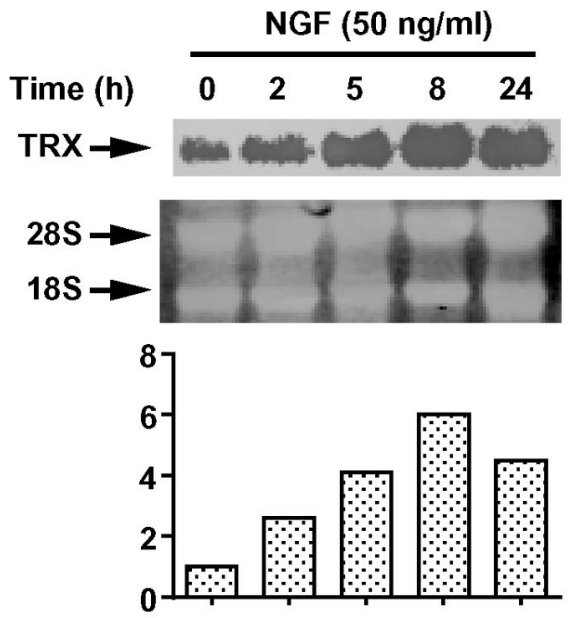

C

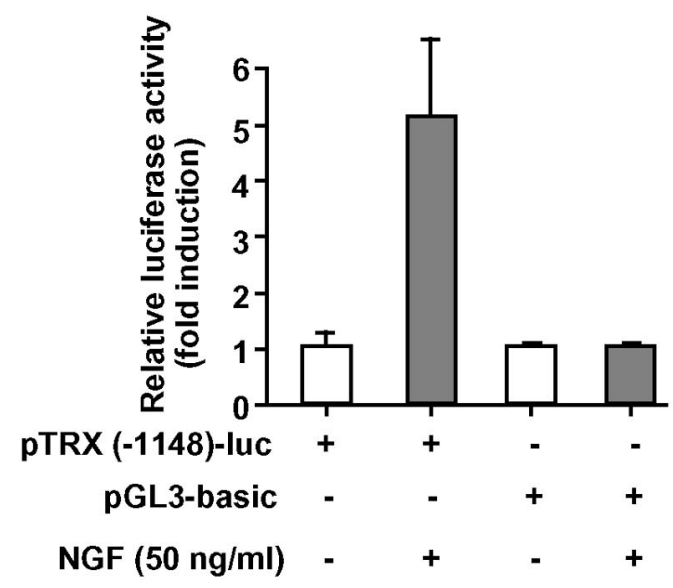

Figure 1. NGF-induced TRX expression. A, Increase in TRX protein caused by NGF. PC12 cells treated with NGF $(50 \mathrm{ng} / \mathrm{ml})$ for 24 and $48 \mathrm{hr}$ were harvested and subjected to detection by Western blotting. The sample loading was monitored by Coomassie brilliant blue (CBB) staining. Similar results were obtained three times. $B$, Increased expression of TRX mRNA induced by NGF. PC12 cells treated with NGF $(50 \mathrm{ng} / \mathrm{ml})$ were harvested at the indicated time points and then analyzed by Northern blotting. The sample loading was monitored by $18 \mathrm{~S}$ and $28 \mathrm{~S}$ RNA. Similar results were obtained twice. Bottom panel, Densitometric analysis of TRX expression normalized by 285 RNA staining. C, Activation of the TRX gene by NGF. PC12 cells were transfected with pTRX vector (-1148) together with pRL-TK and then incubated with or without NGF. The result is representative of three independent experiments.

\section{Identification of the NGF-responsive region in the TRX promoter}

To understand the precise mechanism by which the TRX gene is activated by NGF, luciferase reporter constructs containing various deletion mutants of the TRX promoter region were used. A region of the gene between positions -263 and -217 relative to the translation start site was required for the NGF response (Fig. $2 \mathrm{~A}$ ). This region contains a sequence that resembles the consensus
CRE, indicating the involvement of CRE in the NGF-dependent induction of TRX. We further analyzed the involvement of the CRE-like sequence in NGF responsiveness. Activation of the TRX gene by NGF was impaired in a vector that has mutations in this CRE-like sequence (Fig. 2 B). We next analyzed CRE-binding protein by EMSA. NGF induced specific binding to the sequence, which was abolished by an excess amount of oligonucleotides encoding CRE but not SRE. Moreover, the binding was diminished by anti-CREB antibody but not by control antibody (Fig. 2C).

\section{TRX expression was suppressed by PD98059}

PD98059, mitogen-activated protein kinase kinase (MEK) inhibitor, is known to suppress extracellular signal-regulated kinase (ERK) - and CRE-mediated activation by NGF. Treatment with NGF for $2 \mathrm{~d}$ induced neurite extension of PC12 cells. As reported previously, PD98059 $(50 \mu \mathrm{M})$ suppressed the NGF-induced morphological change in PC12 cells. We then tested the effect of PD98059 on NGF-mediated TRX gene activation. After $24 \mathrm{hr}$ of NGF treatment, PD98059 blocked the NGF-induced activation of the TRX gene (Fig. 3A). After $48 \mathrm{hr}$ of NGF treatment, PD98059 also caused a decrease of TRX protein expression (Fig. 3B).

\section{NGF-induced nuclear translocation of TRX was blocked by PD98059}

ERK is translocated from cytoplasm to nucleus on NGF treatment (Chen et al., 1992). TRX is also translocated from cytoplasm to nucleus on exposure to $\mathrm{H}_{2} \mathrm{O}_{2}$ or UV irradiation (Hirota et al., 1997). To analyze the involvement of TRX in NGF-induced signaling, we studied the subcellular location of TRX on NGF treatment. After $16 \mathrm{hr}$ of NGF (50 ng/ml) treatment, TRX was translocated to nuclei. Nuclear expression of TRX was positive in $86 \pm 3 \%$ of cells treated with NGF, whereas it was negative in control cells. The nuclear translocation of TRX was blocked by PD98059 (Fig. 4A-C). Nuclear expression was defined by costaining with Hoechst 33342 (Fig. 4D,E).

\section{Overexpression of mutant TRX (C32S/C35S) or TRX antisense vector blocked NGF-induced neurite outgrowth of PC12 cells}

We then examined whether TRX is required for NGF-dependent neurite outgrowth in PC12 cells. We transiently transfected PC12 cells with pBI-EGFP, pBI-EGFP-wtTRX, pBIEGFP-antisenseTRX, or pBI-EGFP-dmTRX (32S/35S), in which the redox-active site of TRX was inactivated, together with the pTet-Off vector. The mutant TRX competitively inhibits TRX-dependent activation of transcription factors (Ueno et al., 1999). After transfection, NGF (50 ng/ml) was added to the medium. We observed neurite outgrowth 24 and $48 \mathrm{hr}$ after NGF treatment. Transfected cells were identified by the fluorescence of GFP. Cells with neurites were defined as cells that possessed at least one neurite of greater than one cell body diameter in length. Results are shown as percentages of the number of neuritepositive cells against the total number of transfected cells. At least 100 cells were assessed in each experiment. We repeated experiments three times. Seventy-four $\pm 4 \%$ of cells transfected with the wild-type TRX vector and $56 \pm 2 \%$ of cells transfected with the control vector showed neurite outgrowth. In contrast, $8 \pm 1 \%$ of mutant TRX vector-transfected cells showed neurite outgrowth. In addition, only $17 \pm 1 \%$ of antisense TRX-transfected cells showed neurite outgrowth (Fig. 5). Expression of the TRX dominant negative mutant or antisense TRX vectors may alter NGF-induced cell survival under serum-free conditions. To test 
A
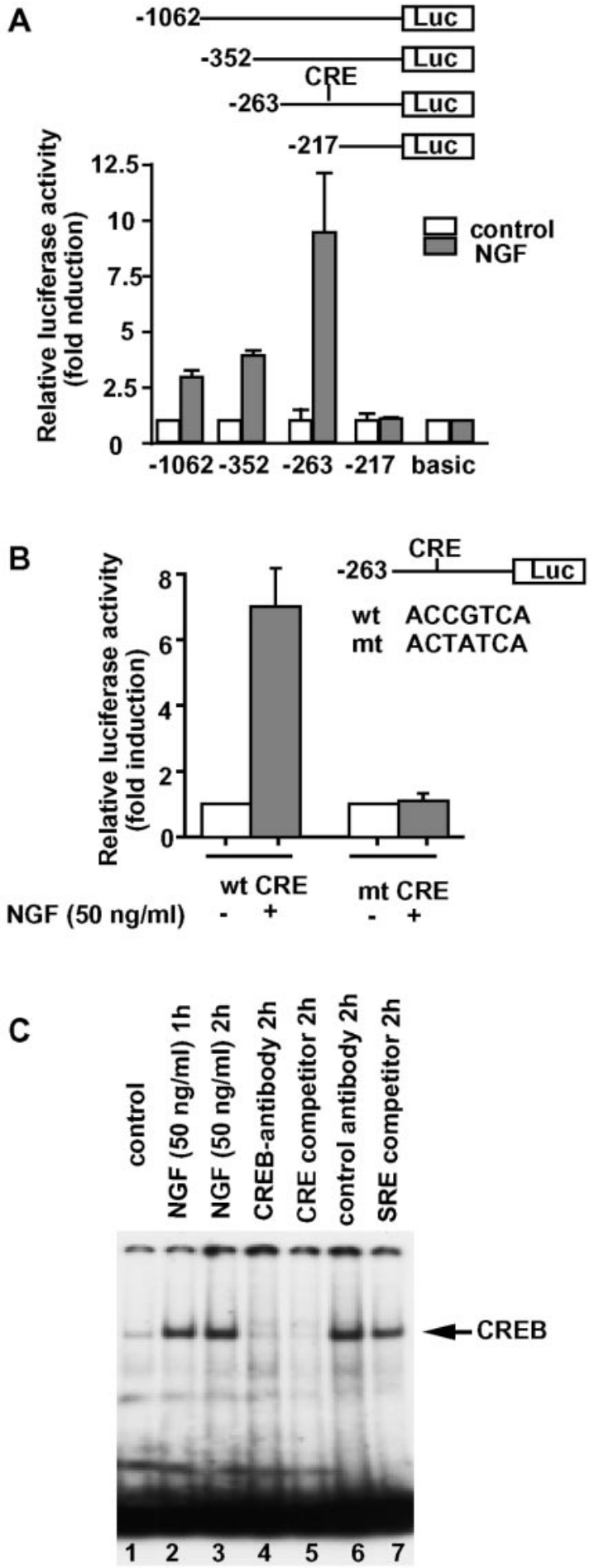

Figure 2. Activation of the TRX genethrough the CRE-like sequence. $A$, Identification of the region responsible for the response to NGF in the TRX promoter. PC12 cells were transfected with the pTRXLuc vectors, as indicated in the top panel, together with pRL-TK. Values shown represent the ratio of luciferase activity of NGF $(50 \mathrm{ng} / \mathrm{mll})$-treated cells to that of untreated cells. The result is representative of three independent experiments. $B$, Disappearance of NGF responsiveness in a vector harboring a mutation in the CRE-like sequence. The wild-type and mutated sequences are indicated in the right panel. Similar results were obtained in four independent experiments. C, EMSA of NGF-induced binding of proteins to the CRE-like sequence. Nuclear extracts from PC12 cells in the absence (lane 1) or presence of $50 \mathrm{ng} / \mathrm{ml} \mathrm{NGF} \mathrm{for} 1 \mathrm{hr}$ (lane 2) and $2 \mathrm{hr}$ (lanes 3-7) were analyzed by EMSA as described in Materials and Methods. Oligonucleotides encompassing wild-type CRE were used as a probe. AntiCREB antibody (dilution 1:10; lane 4), $100 \mathrm{ng}$ of CREwt competitor (lane 5), control antibody (dilution 1:10; lane 6), and $100 \mathrm{ng}$ of SRE competitor (lane 7) were incubated with the reaction mixture before the addition of radiolabeled probes.
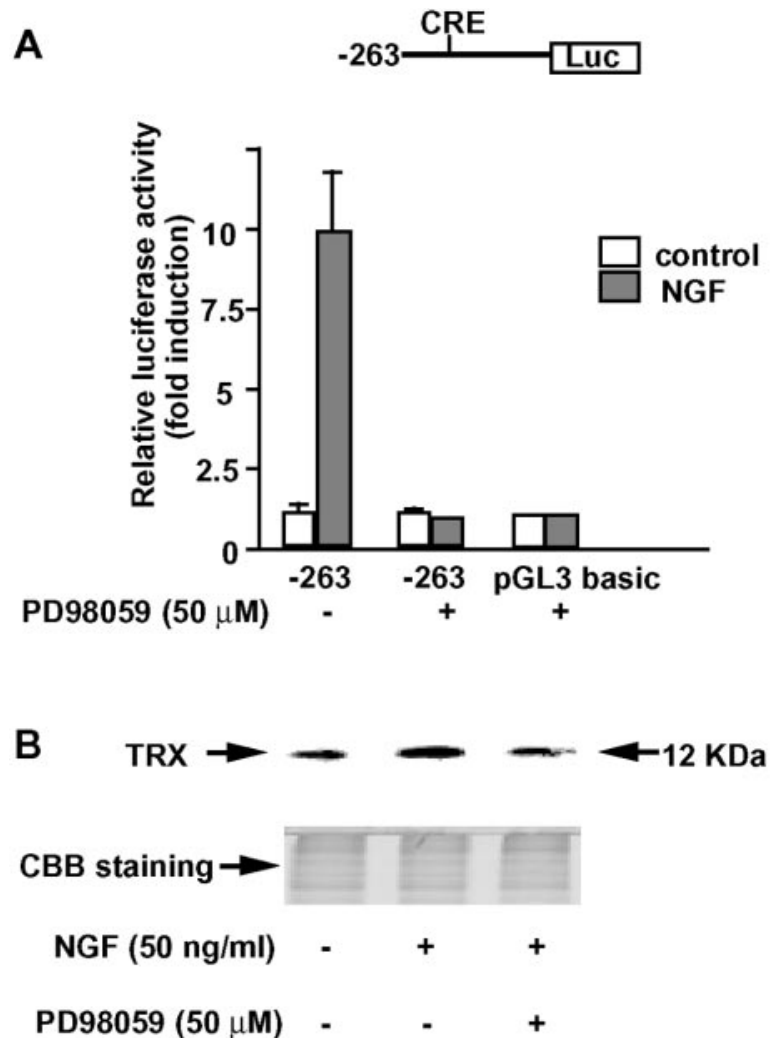

Figure 3. Suppression of TRX expression by PD98059. A, Inhibition of NGF-induced transactivation of TRX by the addition of PD98059. PC12 cells were transfected with the PTRX (-263)Luc vector together with pRL-TK and then treated with NGF $(50 \mathrm{ng} / \mathrm{ml})$ and PD98059 $(50 \mu \mathrm{M})$ for $24 \mathrm{hr}$. Values shown represent the ratio of luciferase activity of cells treated with NGF and PD98059 to that of untreated cells. The result is representative of three independent experiments. B, Suppression of TRX protein expression by PD98059. PC12 cells were treated with NGF $(50 \mathrm{ng} / \mathrm{ml})$ and PD98059 $(50 \mu \mathrm{m})$ for $48 \mathrm{hr}$. Protein samples were fractionated and screened with anti-TRX antibody. The protein loading was monitored by CBB staining. The similar results were obtained three times.

this possibility, we analyzed apoptosis in cells transfected with the control, TRX dominant negative, and antisense TRX vectors under a serum-free condition, $48 \mathrm{hr}$ after NGF treatment, by flow cytometric analysis. Overexpression of the TRX dominant negative or antisense TRX vector did not induce apoptosis under this condition (data not shown). These results suggest that TRX is required for NGF-dependent neurite outgrowth of PC12 cells.

Overexpression of mutant TRX (C32S/C35S) blocked CREmediated c-fos induction by NGF

TRX has been reported to regulate various transcription factors by facilitating either DNA binding (Hirota et al., 1997; Ueno et al., 1999) or coactivator interaction (Ema et al., 1999). Therefore, we analyzed whether TRX is involved in the regulation of NGFmediated activation through CRE. After treatment for $4 \mathrm{hr}$, NGF caused a 40 -fold increase of luciferase activity in pGL3-c-fos $(-99,+42)$ containing CRE but no increase in pGL3-c-fos $(-40$, +42 ), in which the CRE sequence was entirely deleted (Fig. $6 A$ ). The response to NGF of the reporter gene pGL3-c-fos ( -99 , +42 ) was markedly suppressed by transfection with mutant TRX (C32S/C35S). The transactivation of c-fos was suppressed to $75 \%$ by mutant TRX (C32S/C35S) (Fig. 6 B). In contrast, NGF caused a 50-fold increase in luciferase activity in SRE3-luc, which was not suppressed by overexpression of mutant TRX (C32S/C35S) (Fig. 6C). 

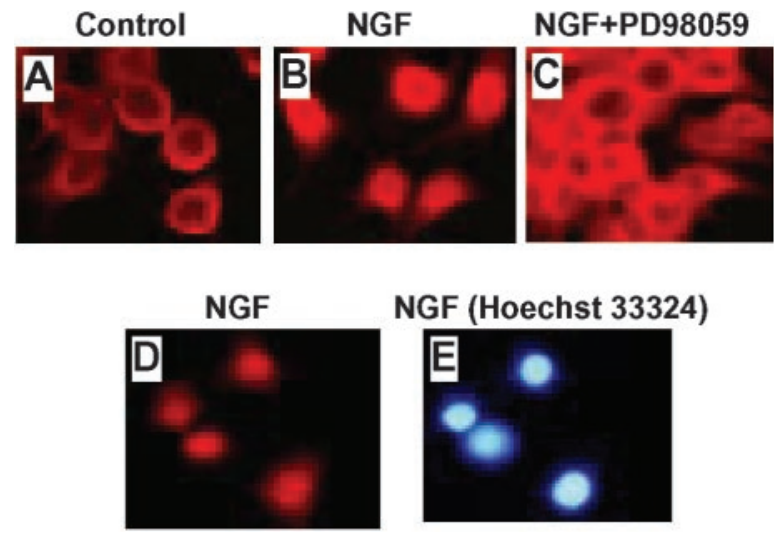

NGF (Hoechst 33324)

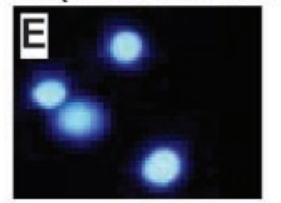

Figure 4. Suppression of NGF-induced TRX nuclear translocation. $A, P C 12$ cells cultured without NGF. B, PC12 cells treated with NGF (50 ng/ml). C, PC12 cells treated with NGF (50 $\mathrm{ng} / \mathrm{ml})$ and PD98059 $(50 \mu \mathrm{m}) . D, P C 12$ cells treated with NGF $(50 \mathrm{ng} / \mathrm{ml})$. These cells are stained

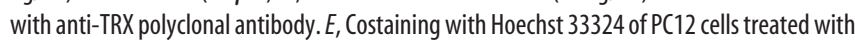
NGF. D, E, Same field. A-C, Examined by a laser confocal microscope. D, E, Examined by a fluorescent microscope.
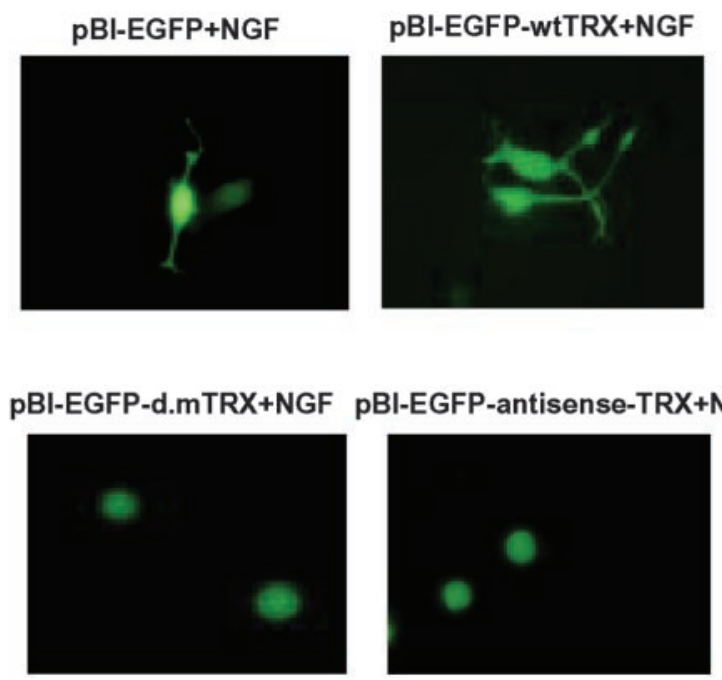

Figure 5. Inhibition of NGF-induced neurite outgrowth by mutant TRX overexpression. PC12 cells were transfected with the pBI-EGFP $(2 \mu \mathrm{g})$, pBI-EGFP-wtTRX $(2 \mu \mathrm{g})$, pBI-EGFP-dmTRX (32S/35S) $(2 \mu \mathrm{g})$, or pBI-EGFP antisenseTRX $(2 \mu \mathrm{g})$ vectors, together with the pTet-0ff vector $(2 \mu \mathrm{g})$, and treated with NGF $(50 \mathrm{ng} / \mathrm{ml})$. After $24 \mathrm{hr}$, these cells were examined with a fluorescent microscope. Similar results were obtained three times.

\section{Discussion}

In the present study, we have shown that NGF induces TRX expression at the protein and mRNA levels in PC12 cells. We identified an NGF-responsive region positioned from -263 to $-217 \mathrm{bp}$ in the TRX gene by a luciferase assay. This region contained a CGTCA sequence, which bears a resemblance to that of the consensus CRE (Montminy et al., 1986). Moreover, insertion of a mutation in the sequence abolished the response to NGF. EMSA analysis showed that NGF-induced binding to the sequence was competed by consensus CRE oligonucleotides and blocked by anti-CREB antibody. In addition, we showed that an MEK inhibitor, PD98059, suppressed NGF-induced TRX expression. NGF-induced CRE activation is mediated by ERK (Impey et al., 1998). These results indicate that the TRX gene is induced by NGF through the ERK and CRE cascade. Studies are in progress to analyze the mechanism of the TRX gene induction by NGF.
A
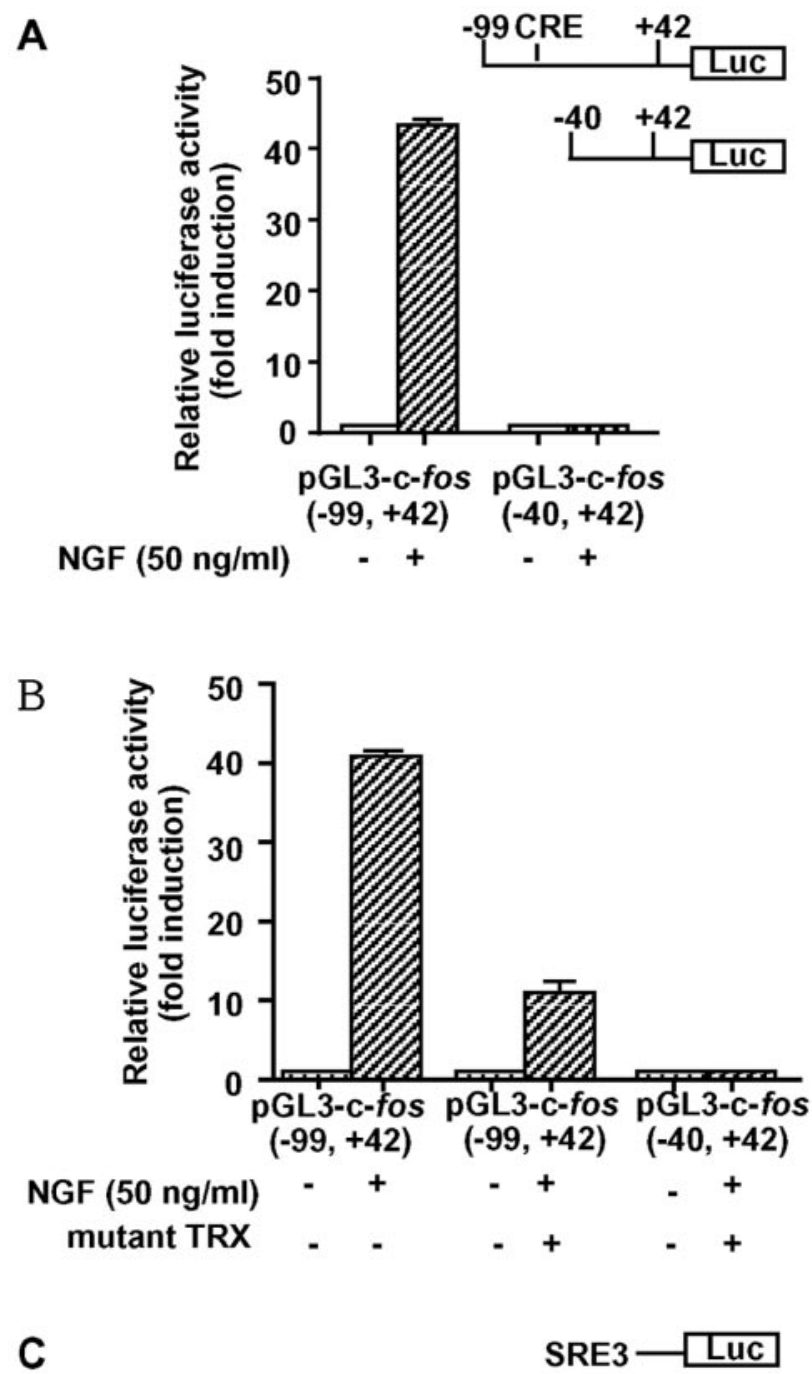

C

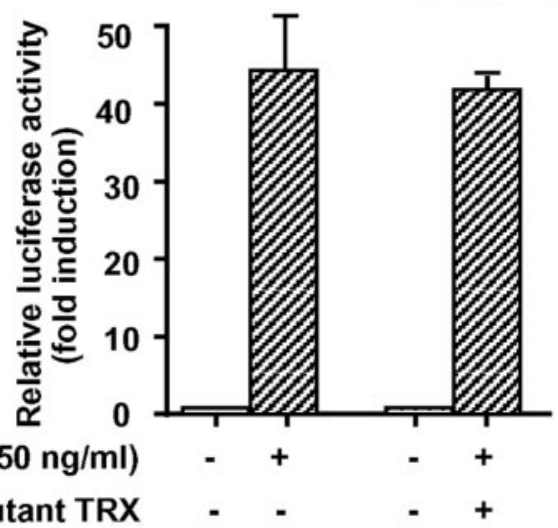

Figure 6. Suppression of CRE-mediated c-fos induction by the dominant negative mutant type of TRX. A, NGF induced c-fos gene activation through CRE. PC12 cells were transfected with pGL3-c-fos $(-40,+42)$ or pGL3-c-fos $(-99,+42)$, as indicated in the top panel, together with pRL-TK and then treated with NGF for $4 \mathrm{hr}$. Values shown represent the ratio of luciferase activity of NGF-treated cells to that of untreated cells. B, Suppression of NGF-induced c-fos gene activation by mutant-type TRX. PC12 cells were cotransfected with the pGL3-c-fos $(-99,+42)$ and pcDNA3 $(1 \mu \mathrm{g})$ or pcDNA3$\operatorname{TRX}(32 \mathrm{~S} / 355)(1 \mu \mathrm{g})$ vectors as indicated, together with pRL-TK. Transfected PC12 cells were treated with NGF for $4 \mathrm{hr}$. Values shown represent the ratio of luciferase activity of NGF-treated cells to that of untreated cells. The result is representative of three independent experiments. Assays were performed in duplicate. C, Effect of mutant-type TRX overexpression on SRE-mediated activation by NGF. PC12 cells were cotransfected with the SRE3-luc and pcDNA3 $(1 \mu \mathrm{g})$ or pcDNA3-TRX (32S/35S) $(1 \mu \mathrm{g})$ vectors, as indicated in the top panel, together with pRL-TK. The result is representative of three independent experiments. Assays were performed in duplicate. 
We also demonstrated that NGF induces nuclear translocation of TRX, as does PMA (Hirota et al., 1997), UV irradiation (Ueno et al., 1999), and hemin (Kim et al., 2001). We showed that PD98059 blocks this effect of NGF, suggesting that ERK is involved in regulating the NGF-induced nuclear translocation of TRX. The mechanism and physiological significance of the translocation should be further investigated. The NGF-induced expression and nuclear translocation of TRX seems to be associated with the NGF-induced outgrowth of PC12 cells, because PD98059 suppressed both the NGF-induced neurite outgrowth and TRX expression as well as nuclear translocation (Figs. 3, 4). More importantly, overexpression of dominant negative mutant TRX and antisense TRX vectors almost completely inhibited the neurite outgrowth (Fig. 5). It is possible that expression of the TRX dominant negative mutant vector changed NGF-induced cell survival. However, overexpression of the dominant negative or antisense TRX vector did not induce apoptosis under a serumfree condition $48 \mathrm{hr}$ after NGF treatment. These results strongly suggest that TRX is required for the neurite outgrowth of PC12 cells induced by NGF.

The IEGs, such as c-fos, have been believed to be required for NGF action. In the upstream regulatory region of the c-fos gene, CRE is critical for regulation of $\mathrm{c}$-fos transcription in response to a variety of extracellular stimuli that induce neural differentiation (Sheng et al., 1988; Ahn et al., 1998). We have shown that overexpression of the dominant negative mutant type of TRX blocks NGF-induced activation of the pGL3-c-fos $(-99,+42)$ reporter gene containing CRE but not pGL3-c-fos $(-40,+42)$ and SRE3luc (Fig. 6B,C). Therefore, overexpression of a dominant negative TRX seemed not to cause a nonspecific effect but seemed to preferentially affect the CRE pathway. The mechanism of the suppression of CRE-mediated activation by a dominant negative TRX should be investigated further. These results indicate that TRX is necessary for NGF signaling through CRE, leading to c-fos expression. NGF induces the c-fos gene to high levels at $1 \mathrm{hr}$ after NGF treatment, whereas augmentation of TRX expression is rather slow. Therefore, the initial phase of c-fos induction may not be attributable to the increased TRX, but the constitutively expressed TRX may potentiate the activation of AP-1. Upregulated TRX may exert its effect through sustained activation of AP-1 or some post-transcriptional mechanism to enhance NGF signaling. TRX regulates the activity of DNA-binding proteins, including Jun and Fos (AP-1), and interacts with an intranuclear reducing molecule, Redox factor 1 (Ref-1; Hirota et al., 1997). AP-1 and Ref-1 have been reported to be involved in differentiation (Sheng and Greenberg, 1990; Chiarini et al., 2000). Recently, we reported that TRX and Ref- 1 regulate the interaction between transcription factors and coactivators (Ema et al., 1999) and that activation of CREB is regulated by TRX (Hirota et al., 2000). Therefore, TRX may augment the interaction of CREB with DNA or coactivators to facilitate NGF signaling. Further study is needed to elucidate the mechanism of involvement of TRX in the NGF signaling pathway.

NGF has been shown to promote axonal regeneration (Hollowell et al., 1990). Endoh et al. (1993) reported neurotrophic activity of TRX for cholinergic neurons. The present results confirmed and expanded this finding, suggesting that TRX is a neurotrophic cofactor that augments the effect of NGF on neurite outgrowth and neuronal regeneration.

NGF acts as a neuronal survival factor and has been shown to prevent the death of axotomized septal neurons (Pallage et al., 1986). The ERK signaling pathway is not only critical for differentiation but also involved in cell survival (Xia et al., 1995). NGF withdrawal causes apoptosis in PC12 cells, which is mediated by p38 MAPK and ASK1 (Xia et al., 1995; Kummer et al., 1997; Kanamoto et al., 2000). TRX has been reported to act as an endogenous inhibitor of ASK1 and p38 MAPK (Saitoh et al., 1998; Hashimoto et al., 1999), and NGF withdrawal also caused downregulation of TRX expression in PC12 cells (J. Bai, H. Nakamura, H. Masutani, and J. Yodoi, unpublished observations). These results indicate that maintenance of the TRX level by NGF plays a role in not only neurite outgrowth but also prevention of neuronal death. A protective role for TRX against neuronal damage has been shown. TRX expression is induced in astroglia after ischemia (Tomimoto et al., 1993). Overexpression of TRX in transgenic mice attenuates focal cerebral ischemic injury (Takagi et al., 1999) and excitotoxic hippocampal injury (Takagi et al., 2000). Decreased expression of TRX in Alzheimer's disease brain has also been reported (Lovell et al., 2000). NGF administration has been proposed for maintaining cholinergic neurons in patients with Alzheimer's disease (Serrano Sanchez et al., 2001). These studies and our results collectively indicate that administration of TRX may enhance the effect of NGF in neuronal diseases such as neurodegenerative disorders. Further study is in progress to clarify the therapeutic potential of TRX for neurodegenerative disorders.

\section{References}

Ahn S, Olive M, Aggarwal S, Krylov D, Ginty DD, Vinson C (1998) A dominant-negative inhibitor of CREB reveals that it is a general mediator of stimulus-dependent transcription of c-fos. Mol Cell Biol 18:967-977.

Boussif O, Lezoualc'h F, Zanta MA, Mergny MD, Scherman D, Demeneix B, Behr JP (1995) A versatile vector for gene and oligonucleotide transfer into cells in culture and in vivo: polyethylenimine. Proc Natl Acad Sci USA 92:7297-7301.

Chen RH, Sarnecki C, Blenis J (1992) Nuclear localization and regulation of erk- and rsk-encoded protein kinases. Mol Cell Biol 12:915-927.

Chiarini LB, Freitas FG, Petrs-Silva H, Linden R (2000) Evidence that the bifunctional redox factor/AP endonuclease Ref- 1 is an anti-apoptotic protein associated with differentiation in the developing retina. Cell Death Differ 7:272-281.

Connor B, Dragunow M (1998) The role of neuronal growth factors in neurodegenerative disorders of the human brain. Brain Res Brain Res Rev 27:1-39.

Ema M, Hirota K, Mimura J, Abe H, Yodoi J, Sogawa K, Poellinger L, FujiiKuriyama Y (1999) Molecular mechanisms of transcription activation by HLF and HIFlalpha in response to hypoxia: their stabilization and redox signal-induced interaction with CBP/p300. EMBO J 18:1905-1914.

Endoh M, Kunishita T, Tabira T (1993) Thioredoxin from activated macrophages as a trophic factor for central cholinergic neurons in vitro. Biochem Biophys Res Commun 192:760-765.

Ginty DD, Bonni A, Greenberg ME (1994) Nerve growth factor activates a Ras-dependent protein kinase that stimulates c-fos transcription via phosphorylation of CREB. Cell 77:713-725.

Greene LA, Tischler AS (1976) Establishment of a noradrenergic clonal line of rat adrenal pheochromocytoma cells which respond to nerve growth factor. Proc Natl Acad Sci USA 73:2424-2428.

Hashimoto S, Matsumoto K, Gon Y, Furuichi S, Maruoka S, Takeshita I, Hirota K, Yodoi J, Horie T (1999) Thioredoxin negatively regulates p38 MAP kinase activation and IL-6 production by tumor necrosis factoralpha. Biochem Biophys Res Commun 258:443-447.

Hirota K, Matsui M, Iwata S, Nishiyama A, Mori K, Yodoi J (1997) AP-1 transcriptional activity is regulated by a direct association between thioredoxin and Ref-1. Proc Natl Acad Sci USA 94:3633-3638.

Hirota K, Matsui M, Murata M, Takashima Y, Cheng FS, Itoh T, Fukuda K, Yodoi J (2000) Nucleoredoxin, glutaredoxin, and thioredoxin differentially regulate NF-kappaB, AP-1, and CREB activation in HEK293 cells. Biochem Biophys Res Commun 274:177-182.

Hollowell JP, Villadiego A, Rich KM (1990) Sciatic nerve regeneration across gaps within silicone chambers: long-term effects of NGF and consideration of axonal branching. Exp Neurol 110:45-51.

Holmgren A (1985) Thioredoxin. Annu Rev Biochem 54:237-271. 
Hori K, Katayama M, Sato N, Ishii K, Waga S, Yodoi J (1994) Neuroprotection by glial cells through adult $\mathrm{T}$ cell leukemia-derived factor/human thioredoxin (ADF/TRX). Brain Res 652:304-310.

Impey S, Obrietan K, Wong ST, Poser S, Yano S, Wayman G, Deloulme JC, Chan G, Storm DR (1998) Cross talk between ERK and PKA is required for $\mathrm{Ca}^{2+}$ stimulation of CREB-dependent transcription and ERK nuclear translocation. Neuron 21:869-883.

Kanamoto T, Mota M, Takeda K, Rubin LL, Miyazono K, Ichijo H, Bazenet CE (2000) Role of apoptosis signal-regulating kinase in regulation of the c-Jun N-terminal kinase pathway and apoptosis in sympathetic neurons. Mol Cell Biol 20:196-204.

Kane DJ, Sarafian TA, Anton R, Hahn H, Gralla EB, Valentine JS, Ord T, Bredesen DE (1993) Bcl-2 inhibition of neural death: decreased generation of reactive oxygen species. Science 262:1274-1277.

Kaplan DR, Martin-Zanca D, Parada LF (1991) Tyrosine phosphorylation and tyrosine kinase activity of the trk proto-oncogene product induced by NGF. Nature 350:158-160.

Kim YC, Masutani H, Yamaguchi Y, Itoh K, Yamamoto M, Yodoi J (2001) Hemin-induced activation of the thioredoxin gene by Nrf2: a differential regulation of the antioxidant responsive element by a switch of its binding factors. J Biol Chem 276:18399-18406.

Kummer JL, Rao PK, Heidenreich KA (1997) Apoptosis induced by withdrawal of trophic factors is mediated by p38 mitogen-activated protein kinase. J Biol Chem 272:20490-20494.

Lo DC (1992) Signal transduction and regulation of neurotrophins. Curr Opin Neurobiol 2:336-340.

Lovell MA, Xie C, Gabbita SP, Markesbery WR (2000) Decreased thioredoxin and increased thioredoxin reductase levels in Alzheimer's disease brain. Free Radic Biol Med 28:418-427.

Mansur K, Iwahashi Y, Kiryu-Seo S, Su Q, Namikawa K, Yodoi J, Kiyama H (1998) Up-regulation of thioredoxin expression in motor neurons after nerve injury. Brain Res Mol Brain Res 62:86-91.

Maruyama T, Kitaoka Y, Sachi Y, Nakanoin K, Hirota K, Shiozawa T, Yoshimura Y, Fujii S, Yodoi J (1997) Thioredoxin expression in the human endometrium during the menstrual cycle. Mol Hum Reprod 3:989-993.

Masutani H, Magnaghi-Jaulin L, Ait-Si-Ali S, Groisman R, Robin P, HarelBellan A (1997) Activation of the c-fos SRE through SAP-1a. Oncogene 15:1661-1669.

Masutani H, Ueno M, Ueda S, Yodoi J (1999) Role of thioredoxin and redox regulation in oxidative stress response and signaling. In: Antioxidant and redox regulation of genes (Sen CK, Sies H, Baeuerle PA, eds), pp 297-311. San Diego, Academic.

Milbrandt J (1986) Nerve growth factor rapidly induces c-fos mRNA in PC12 rat pheochromocytoma cells. Proc Natl Acad Sci USA 83:4789-4793.

Montminy MR, Sevarino KA, Wagner JA, Mandel G, Goodman RH (1986) Identification of a cyclic-AMP-responsive element within the rat somatostatin gene. Proc Natl Acad Sci USA 83:6682-6686.

Nakamura H, Matsuda M, Furuke K, Kitaoka Y, Iwata S, Toda K, Inamoto T, Yamaoka Y, Ozawa K, Yodoi J (1994) Adult T cell leukemia-derived factor/human thioredoxin protects endothelial F-2 cell injury caused by activated neutrophils or hydrogen peroxide. Immunol Lett 42:75-80.

Nakamura H, Nakamura K, Yodoi J (1997) Redox regulation of cellular activation. Annu Rev Immunol 15:351-369.

Nishiyama A, Matsui M, Iwata S, Hirota K, Masutani H, Nakamura H, Takagi Y, Sono H, Gon Y, Yodoi J (1999) Identification of thioredoxin-binding protein-2/vitamin $\mathrm{D}(3)$ up-regulated protein 1 as a negative regulator of thioredoxin function and expression. J Biol Chem 274:21645-21650.

Pallage V, Toniolo G, Will B, Hefti F (1986) Long-term effects of nerve growth factor and neural transplants on behavior of rats with medial septal lesions. Brain Res 386:197-208.
Saitoh M, Nishitoh H, Fujii M, Takeda K, Tobiume K, Sawada Y, Kawabata M, Miyazono K, Ichijo H (1998) Mammalian thioredoxin is a direct inhibitor of apoptosis signal-regulating kinase (ASK) 1. EMBO J 17:2596-2606.

Serrano Sanchez T, Robinson Agramonte M, Lorigados Pedre L, Diaz Armesto I, Gonzalez Fraguela ME, Dorta-Contreras AJ (2001) Endogenous nerve growth factor in patients with Alzheimer's disease. Rev Neurol 32:825-828.

Sheng M, Greenberg ME (1990) The regulation and function of c-fos and other immediate early genes in the nervous system. Neuron 4:477-485.

Sheng M, Dougan ST, McFadden G, Greenberg ME (1988) Calcium and growth factor pathways of c-fos transcriptional activation require distinct upstream regulatory sequences. Mol Cell Biol 8:2787-2796.

Tagaya Y, Maeda Y, Mitsui A, Kondo N, Matsui H, Hamuro J, Brown N, Arai K, Yokota T, Wakasugi H, Yodoi J (1989) ATL-derived factor (ADF), an IL-2 receptor/Tac inducer homologous to thioredoxin; possible involvement of dithiol-reduction in the IL-2 receptor induction. EMBO J 8:757-764.

Takagi Y, Horikawa F, Nozaki K, Sugino T, Hashimoto N, Yodoi J (1998a) Expression and distribution of redox regulatory protein, thioredoxin during transient focal brain ischemia in the rat. Neurosci Lett 251:25-28.

Takagi Y, Tokime T, Nozaki K, Gon Y, Kikuchi H, Yodoi J (1998b) Redox control of neuronal damage during brain ischemia after middle cerebral artery occlusion in the rat: immunohistochemical and hybridization studies of thioredoxin. J Cereb Blood Flow Metab 18:206-214.

Takagi Y, Gon Y, Todaka T, Nozaki K, Nishiyama A, Sono H, Hashimoto N, Kikuchi H, Yodoi J (1998c) Expression of thioredoxin is enhanced in atherosclerotic plaques and during neointima formation in rat arteries. Lab Invest 78:957-966.

Takagi Y, Mitsui A, Nishiyama A, Nozaki K, Sono H, Gon Y, Hashimoto N, Yodoi J (1999) Overexpression of thioredoxin in transgenic mice attenuates focal ischemic brain damage. Proc Natl Acad Sci USA 96:4131-4136.

Takagi Y, Hattori I, Nozaki K, Mitsui A, Ishikawa M, Hashimoto N, Yodoi J (2000) Excitotoxic hippocampal injury is attenuated in thioredoxin transgenic mice. J Cereb Blood Flow Metab 20:829-833.

Taniguchi Y, Taniguchi-Ueda Y, Mori K, Yodoi J (1996) A novel promoter sequence is involved in the oxidative stress-induced expression of the adult T-cell leukemia-derived factor (ADF)/human thioredoxin ( $\operatorname{Trx}$ ) gene. Nucleic Acids Res 24:2746-2752.

Thomas SM, DeMarco M, D’Arcangelo G, Halegoua S, Brugge JS (1992) Ras is essential for nerve growth factor- and phorbol ester-induced tyrosine phosphorylation of MAP kinases. Cell 68:1031-1040.

Tomimoto H, Akiguchi I, Wakita H, Kimura J, Hori K, Yodoi J (1993) Astroglial expression of ATL-derived factor, a human thioredoxin homologue, in the gerbil brain after transient global ischemia. Brain Res 625:1-8.

Treisman R (1986) Identification of a protein-binding site that mediates transcriptional response of the c-fos gene to serum factors. Cell 46:567-574.

Trouche D, Grigoriev M, Lenormand JL, Robin P, Leibovitch SA, SassoneCorsi P, Harel-Bellan A (1993) Repression of c-fos promoter by MyoD on muscle cell differentiation. Nature 363:79-82.

Ueno M, Masutani H, Arai RJ, Yamauchi A, Hirota K, Sakai T, Inamoto T, Yamaoka Y, Yodoi J, Nikaido T (1999) Thioredoxin-dependent redox regulation of p53-mediated p21 activation. J Biol Chem 274:35809-35815.

Xia Z, Dickens M, Raingeaud J, Davis RJ, Greenberg ME (1995) Opposing effects of ERK and JNK-p38 MAP kinases on apoptosis. Science 270:1326-1331.

Yamamoto M, Sato N, Tajima H, Furuke K, Ohira A, Honda Y, Yodoi J (1997) Induction of human thioredoxin in cultured human retinal pigment. Exp Eye Res 65:645-652. 